\title{
Comparative proteomic and genomic analyses of Brucella abortus biofilm and planktonic cells
}

\author{
TAISHAN TANG ${ }^{1,2}$, GUOQIANG CHEN $^{3}$, AIZHEN GUO $^{4}$, YE XU $^{2}$, LINLI ZHAO ${ }^{5}$, \\ MENGRUI WANG ${ }^{2}$, CHENGPING LU $^{1}$, YUAN JIANG ${ }^{2}$ and CHANGYIN ZHANG ${ }^{2}$ \\ ${ }^{1}$ Key Laboratory of Animal Bacteriology, Ministry of Agriculture, Nanjing Agricultural University, Nanjing, Jiangsu 210095; \\ ${ }^{2}$ Animal, Plant and Food Inspection Center, Jiangsu Entry Exit Inspection and Quarantine Bureau, Nanjing, \\ Jiangsu 210001; ${ }^{3}$ Division of Animal and Plant Quarantine Supervision, Suzhou Entry Exit Inspection and \\ Quarantine Bureau, Suzhou, Jiangsu 215021; ${ }^{4}$ College of Veterinary Medicine, Huazhong Agricultural University, \\ Wuhan, Hubei 430070; ${ }^{5}$ The Inspection and Quarantine Technology Center, Inner Mongolia Entry \\ Exit Inspection and Quarantine Bureau, Hohhot, Inner Mongolia 010020, P.R. China
}

Received December 7, 2018; Accepted July 26, 2019

DOI: $10.3892 / \mathrm{mmr} .2019 .10888$

\begin{abstract}
The present study aimed to explore the differences in protein and gene expression of Brucella abortus cultured under biofilm and planktonic conditions. The proteins unique to biofilms and planktonic B. abortus were separated by two-dimensional (2-D) electrophoresis and then identified by matrix-assisted laser desorption/ionization-tandem time of flight-mass spectrometry (MALDI-TOF/TOF-MS). High-throughput sequencing and bioinformatic analyses were performed to identify differentially expressed genes between $B$. abortus cultured under biofilm and planktonic conditions. The proteins and genes identified by proteomic and genomic analyses were further evaluated via western blot and reverse transcription-quantitative polymerase chain reaction (RT-qPCR) analyses. 2-D electrophoresis identified 20 differentially expressed protein spots between biofilms and planktonic cells, which corresponded to 18 individual proteins (12 downregulated and 6 upregulated) after MALDI-TOF/TOF-MS analysis, including elongation factor Tu and enolase. RT-qPCR analysis revealed that all of the 18 genes were downregulated in biofilms compared with planktonic cells. Western blot analysis identified 9 downregulated and 3 upregulated proteins. High-throughput
\end{abstract}

Correspondence to: $\mathrm{Dr}$ Chengping Lu, Key Laboratory of Animal Bacteriology, Ministry of Agriculture, Nanjing Agricultural University, 1 Weigang, Xuanwu, Nanjing, Jiangsu 210095, P.R. China E-mail: lucp@njau.edu.cn

Dr Yuan Jiang, Animal, Plant and Food Inspection Center, Jiangsu Entry Exit Inspection and Quarantine Bureau, 99 Zhonghua Road, Nanjing, Jiangsu 210001, P.R. China

E-mail: jiangy@jsciq.gov.cn

Key words: Brucella abortus, biofilm, planktonic condition, proteomics, bioinformatics analysis sequencing and bioinformatic analyses identified 14 function and pathway-associated genes (e.g., BAbS19_I14970). RT-qPCR analysis of the 14 genes showed that they were upregulated in biofilm compared with in planktonic state. In conclusion, these differentially expressed genes may play important roles in bacterial defense, colonization, invasion, and virulence.

\section{Introduction}

Brucella is a group of $\alpha-2$ Proteobacteria that has a great impact on animal and human health worldwide (1). Infection with Brucella results in brucellosis, one of the most common bacterial zoonotic diseases in humans and cattle globally (2). An estimated 500,000 cases of brucellosis occur each year globally (3). Brucellosis can not only lead to the reproductive failure of livestock but also decrease human productivity. As a result, Brucella species have been regarded as potential agricultural, animal husbandry, civilian and even bioterrorism agents $(4,5)$.

During chronic infection, bacteria can organize themselves into matrix-enclosed microcolonies or aggregates, termed biofilms $(6,7)$. Biofilm formation is a critical survival mechanism for bacteria in the environment (8). Altered gene and protein expression in biofilms is responsible for cell virulence, adherence and drug resistance $(9,10)$. Additionally, biofilm-grown microorganisms have an inherent lack of susceptibility to antibiotics (11-13). Brucella melitensis (B. melitensis) has been suggested to form biofilms during its life cycle (14). Wild-type B. abortus can also develop biofilms under nutritionally deficient, microaerobic conditions (15). Previous studies have investigated several virulence and drug resistance-associated proteins from planktonic Brucella, such as lipopolysaccharide (16), B lymphocyte mitogen (17) and outer membrane proteins (18). However, numerous different types of bacterial infections are presumed to be due to bacteria growing in a biofilm state including cystic fibrosis-related lung infections, biomaterial-related infections, chronic wounds, 
and endocarditis. The USA National Institutes of Health has estimated that $80 \%$ of all infections are biofilm-related (19). However, little is known concerning the proteins associated with biofilm-mediated infections.

The present study investigated differences in protein and gene expression of B. abortus cultured under biofilm compared with planktonic conditions. The differential proteins unique to biofilms and planktonic B. abortus were identified by employing two-dimensional (2-D) electrophoresis and matrix-assisted laser desorption/ionization-tandem time of flight-mass spectrometry (MALDI-TOF/TOF-MS) analyses. The differential genes were identified by high-throughput sequencing and bioinformatic analysis. Findings of the current study may help to understand the underlying molecular mechanisms that control biofilm formation in B. abortus.

\section{Materials and methods}

Bacterial strains and culture conditions. B. abortus strain isolate A3313 was used in this study, which was isolated from the abortus of dairy cows in Hohhot District, Inner Mongolia, China. The A3313 strain was grown in Brucella broth medium (BD Biosciences) at $37^{\circ} \mathrm{C}$ with $5 \% \mathrm{CO}_{2}$.

All the experiments related to the cultivation of Brucella and its biofilms, as well as the operation of viable bacteria were conducted in a Biosafety Level 3 Laboratory in the College of Veterinary Medicine, Huazhong Agricultural University (Wuhan, China). For the experiments of electron microscope observation, 2-D electrophoresis, high-throughput sequencing and reverse transcription-quantitative polymerase chain reaction (RT-qPCR) analysis, the Brucella and its biofilm were effectively inactivated with glutaraldehyde or bacterial lysate before being removed from the Biosafety Level 3 Laboratory.

Biofilm culture and microscopic observation. Brucella broth was added to 6-well cell culture plates. A clean coverslip sterilized by autoclaving $\left(121^{\circ} \mathrm{C}, 20 \mathrm{~min}\right)$ was then put in each well, and the A3313 bacterial suspension was inoculated on the coverslip at $2 \mathrm{ml} / \mathrm{well}$. The culture plate was placed at $37^{\circ} \mathrm{C}$ with $5 \% \mathrm{CO}_{2}$, and the culture medium was changed every $48 \mathrm{~h}$ until a complete biofilm was formed. The coverslips were taken out, gently washed three times with phosphate-buffered saline (PBS; $30 \mathrm{mM}, \mathrm{pH} 7.4$ ), and then fixed immediately with $2.5 \%$ glutaraldehyde for $6-8 \mathrm{~h}$ at $4^{\circ} \mathrm{C}$. After being washed with PBS, biofilms were stained with $200 \mu 11 \%$ crystal violet (Ding Bei Biological Technology Co., Ltd.) for $20 \mathrm{~min}$ at room temperature. These procedures were conducted to protect biofilms from falling off from the abiotic surfaces. The biofilms were observed under a phase-contrast light microscope (magnification, x20) (Axiovert 135; Zeiss AG).

For scanning electron microscope observation, biofilms were fixed with $2 \%$ osmic acid at room temperature until black. After washing with 0.1 M PBS for three times, the samples underwent sequential dehydration with gradient ethanol solutions $(30,50,70$ and $90 \%)$ for $15 \mathrm{~min}$ each. Then, samples were dehydrated with $100 \%$ ethanol twice (15 min each), and dried with a critical point dryer. The dry samples were fixed on the sample stage with conducting resin, and sprayed gold with ion sputtering equipment $(15 \mathrm{~mA})$ for $2 \mathrm{~min}$. The biofilms were observed under a scanning electron microscope.
2-D electrophoresis. Biofilms and planktonic bacteria were used for 2-D electrophoresis. For biofilm culture, the A3313 strain was grown in Brucella broth medium in Petri dishes at $37^{\circ} \mathrm{C}$ and $5 \% \mathrm{CO}_{2}$. The culture medium was changed every $48 \mathrm{~h}$ for 8 days. After removing the supernatant, the plates were rinsed twice with PBS. Biofilms were detached by scraping. Planktonic B. abortus was cultured in the same condition. The culture medium was collected and centrifugally washed twice with PBS. The planktonic B. abortus was resuspended with PBS.

Protein was precipitated as previously described $(10,20)$. The biofilm and planktonic bacteria were harvested by centrifugation $(6,000 \mathrm{x} \mathrm{g})$ at $4^{\circ} \mathrm{C}$ for $10 \mathrm{~min}$. The bacteria were washed four times with a solution containing $3 \mathrm{mM}$ $\mathrm{KCl}, 68 \mathrm{mM} \mathrm{NaCl}, 9 \mathrm{mM} \mathrm{NaH} \mathrm{PO}_{4}$ and $115 \mathrm{mM} \mathrm{KH}_{2} \mathrm{PO}_{4}$, and then resuspended in lysis buffer ( $7 \mathrm{M}$ urea, $2 \mathrm{M}$ thiourea, 4\% CHAPS, $10 \mathrm{mM}$ DTT and 2\% Pharmalyte $\mathrm{pH} 3-10$ ) with protease inhibitor. After ultrasonic decomposition on ice at $40 \%$ maximum power for 90 cycles (5 sec on, $10 \mathrm{sec}$ off; the ultrasound conditions were the same for biofilm disruption and planktonic cells), unbroken cells and the cell debris were incubated at $25^{\circ} \mathrm{C}$ for $30 \mathrm{~min}$, and removed by centrifugation $(10,000 \mathrm{x} \mathrm{g})$ for $30 \mathrm{~min}$ at $25^{\circ} \mathrm{C}$. Proteins in the supernatant were precipitated in $10 \%$ trichloroacetic acid (TCA) on ice for $30 \mathrm{~min}$. Precipitated proteins were washed with chilled acetone and then centrifuged at $10,000 \mathrm{x}$ g for $10 \mathrm{~min}$ at $4^{\circ} \mathrm{C}$. The air-dried proteins were dissolved in $400 \mu 1$ sample preparation solution [2-D lysate: $9.5 \mathrm{M}$ urea, 4\% CHAPS, 2\% (v/v) ampholytes, and $60 \mathrm{mM}$ DTT; $10 \mu 150$ XProtein Inhibitor Cocktail Set I (Merck KGaA) was added into $500 \mu 1$ 2-D lysate] at $25^{\circ} \mathrm{C}$ for $30 \mathrm{~min}$ and centrifuged at $10,000 \mathrm{x}$ g for $20 \mathrm{~min}$ at $25^{\circ} \mathrm{C}$. The protein concentration was determined via a Bradford protein assay.

Proteins $(200 \mu \mathrm{g})$ were separated by 2-D electrophoresis. Isoelectric focusing for the first dimension was performed in precast Immobiline DryStrips (GE Healthcare Life Sciences) with a nonlinear gradient of $\mathrm{pH} 3$ to 10 in an Ethan IPGphor Isoelectric Focusing System (GE Healthcare Life Sciences) according to the manufacturer's instructions. The electrophoresis conditions were $30 \mathrm{~V}$ for $12 \mathrm{~h}, 500 \mathrm{~V}$ for $1 \mathrm{~h}, 1,000 \mathrm{~V}$ for $1 \mathrm{~h}, 8,000 \mathrm{~V}$ for $8 \mathrm{~h}$ and $500 \mathrm{~V}$ for $4 \mathrm{~h}$. The second dimension (SDS-PAGE) was conducted vertically in a Hofer SE 600 (GE Healthcare Life Sciences) using 12.5\% polyacrylamide gels. The resolved proteins were then stained with silver for $30 \mathrm{~min}$ at room temperature and scanned with UMax Powerlook 2110Xl (GE Healthcare Life Sciences). All experiments were performed in triplicate. The gels were analyzed with the Image Master Platinum version 5.0 software (GE Healthcare Life Sciences). The normalized protein amount for each protein spot was calculated as the ratio of that spot volume to the total spot volume on the gel. Significant differences between two groups were determined using the Student's t-test, and a fold change $\geq 1.5$ was considered the threshold value.

MS analysis. The differentially expressed protein spots were excised from the 2-D gels and then subjected to MALDI-TOF/TOF-MS analysis (Shanghai Applied Protein Technology Co. Ltd.). Before MS analysis, the protein spots were digested in-gel by $0.1 \mathrm{mg} / \mathrm{ml}$ trypsin for $2 \mathrm{~h}$ at $37^{\circ} \mathrm{C}$ 
and desalinated by Ziptip (EMD Millipore). The digested samples were then freeze-dried. After being re-dissolved, $1 \mu 1$ samples were spotted on the target plate (Immobiline DryStrips; $13 \mathrm{~cm}, \mathrm{pH} 3-10 \mathrm{NL}$ ) with air drying, and then $0.5 \mu \mathrm{l}$ supersaturated $\alpha$-cyano-4-hydroxycinnamic acid matrixes (Sigma-Aldrich; Merck KGaA) prepared in 50\% acetonitrile with $0.1 \%$ trifluoroacetic acid were spotted and naturally dried. All MALDI-MS and MS/MS data were acquired in the positive reflectron ion mode on a 4800 Plus MALDI TOF/TOF Analyzer (AB Sciex LLC). Samples were irradiated by a $355-\mathrm{nm}$ Nd:YAG laser $(355 \mathrm{~nm})$, and the acceleration voltage was $2 \mathrm{kV}$. The scanned area for MS was 800-4,000 Da, and the parent ion with signal:noise ratio $>50$ was selected for MS/MS analysis. Data from MALDI-MS and MS/MS were subjected to a Database Search from NCBI or Uniprot (NCBI preferentially) using Mascot version 2.2 software (Matrix Science), and a Mascot score was calculated. The MS/MS spectra were subjected to similarity searches using the BLASTX algorithm. The parameter settings were trypsin digestion, fixed modification of carbamidomethyl, dynamical modification of oxidation (M), unrestricted protein mass, peptide mass tolerance for monoisotopic data of $\pm 100 \mathrm{ppm}$, fragment mass tolerance of $\pm 0.4 \mathrm{Da}$, peptide charge state of $1+$, and one maximum missed cleavage.

High-throughput sequencing. RNA sequencing of the biofilms and planktonic bacteria were performed at Genergy Biotechnology Co., Ltd. Total RNA was isolated and examined by NanoDrop spectrophotometer (NanoDrop Technologies; Thermo Fisher Scientific, Inc.) and 1\% agarose gel electrophoresis (Tanon Science and Technology Co., Ltd.). An RNA library was then constructed and sequenced on the Illumina HiSeq 2500 platform (Illumina, Inc.). The data are available at National Center for Biotechnology Information under the accession numbers SRX1604658 (biofilm conditions; http://www.ncbi.nlm.nih.gov/sra/?term=SRX1604658) and SRX1604659 (planktonic conditions; http://www.ncbi.nlm. nih.gov/sra/SRX1604659/).

Bioinformatics analyses. The raw reads were evaluated using RSeQC 2.3.2 (http://rseqc.sourceforge.net/) (21), and sequence alignment was conducted with TopHat 2.0.10 (http://ccb.jhu. edu/software/tophat/index.shtml) (22). The remaining reads were used for the following analyses.

The mRNA expression levels were detected based on Cufflinks 2.2.1 (http://cole-trapnell-lab.github.io/cufflinks/) software (23). Differentially expressed mRNAs were defined based on strict criteria [q value $\leq 0.05$, and $\log 2$ (fold change) $\geq 1$ ] using the Cuffdiff program (23). Functional annotation of differentially expressed genes was carried out using various bioinformatics procedures, including Gene Ontology (GO) (24) and Kyoto Encyclopedia of Genes and Genomes (KEGG, Kolmogorov-Smirnov value <0.05) (25).

$R T-q P C R$. The mRNA levels of differential proteins identified through 2-D electrophoresis and function-associated genes identified by high-throughput sequencing and bioinformatics analyses were detected via RT-qPCR according a previously described method (26). In brief, total RNA was isolated from biofilms and planktonic cells $\left(1 \times 10^{6}\right.$ cells) of the A3313 strain using a Takara MiniBEST Universal RNA Extraction kit (Takara Biotechnology Co., Ltd.). The RNA quality and concentration were determined by a NanoDrop 2000c spectrophotometer (Thermo Fisher Scientific, Inc.). The RNA was reverse-transcribed into cDNA using a PrimeScript RT reagent kit (Takara Biotechnology Co., Ltd.; $42^{\circ} \mathrm{C}$ for $15 \mathrm{~min}$ ). The $16 \mathrm{~S}$ rRNA housekeeping gene was amplified as the internal control. The specific primers are listed in Table SI. The SYBR Green PCR method was performed using an SYBR Premix Ex Taq kit (Takara Biotechnology Co., Ltd.). The qPCR reaction was carried out under the following conditions: $95^{\circ} \mathrm{C}$ for $30 \mathrm{sec}, 40$ cycles of $95^{\circ} \mathrm{C}$ for $3 \mathrm{sec}$ and $60^{\circ} \mathrm{C}$ for $30 \mathrm{sec}$. Relative mRNA expression ratios of selected genes were calculated with the $2^{-\Delta \Delta \mathrm{Cq}}$ method (27). The experiment was performed with three replications.

Western blot analysis. The levels of differentially expressed proteins identified through 2-D electrophoresis, described above, were measured by western blotting. Briefly, cells were lysed in RIPA buffer (Sigma-Aldrich; brand of Merck $\mathrm{KGaA}$ ), and the protein concentration was measured using BCA Protein Assay Kit (Thermo Fisher Scientific, Inc.). Protein samples $(20 \mu \mathrm{g})$ were separated using $12 \%$ SDS-PAGE and transferred onto a polyvinylidene fluoride membrane (GE Healthcare), and the membrane was blocked with $100 \mathrm{mM}$ Tris, $150 \mathrm{mM} \mathrm{NaCl}, 0.05 \%$ Tween-20 (TBST), containing 5\% dry milk powder for $2 \mathrm{~h}$ at room temperature. Then, the blocked membrane was incubated with sera from primary antibodies [hypothetical protein BAbS19_I16470 (1:1,000; cat. no. orb309412; Biorbyt Ltd.); chaperone protein DnaJ (1:1,000; cat. no. PA3-018; Invitrogen; Thermo Fisher Scientific, Inc.); elongation factor Tu $(1: 1,000$; cat.no. ab210089; Abcam); Chaperonin Cpn60/TCP-1 (1:1,000; cat. no. 3094R-100; BioVision, Inc.); polyprenyl synthetase (1:1,000; cat. no. ab80647; Abcam); periplasmic binding protein (1:1,000; cat. no. M30934-1; Wuhan Boster Biological Technology, Ltd.); enolase (1:1,000; cat. no. sc-271384; Santa Cruz Biotechnology, Inc.); acetyl-CoA carboxylase, a subunit (1:1,000; cat. no. MAB6898; R\&D Systems, Inc.); tryptophanyl-tRNA synthetase (1:1,000; cat. no. ab31536; Abcam); aspartate-semialdehyde dehydrogenase (1:1,000; cat. no. EM1708-10a; Jingke Huaxue; exosporium protein B (1:1,000; cat. no. ab92932; Abcam); enoyl-(acyl carrier protein) reductase (1:1,000; cat. no. abx109426; Abbexa Ltd.); Omp16 (1:1,000; cat. no. ab93127; Abcam)] for $2 \mathrm{~h}$ at room temperature and then incubated with horseradish peroxidase-labeled secondary antibodies (1:5,000; cat. no. 29139; Invitrogen; Thermo Fisher Scientific, Inc.) in blocking buffer for $1 \mathrm{~h}$ at room temperature. After washing with $0.05 \%$ Tween-20 (TBST), the membranes were incubated with DAB substrate (Tiangen Biotech Co., Ltd.) for $10 \mathrm{~min}$ at room temperature. Outer membrane protein 16 was used as a loading control. The western blot bands were visualized using the Millipore ECL Western Blotting Detection System (EMD Millipore).

Statistical analysis. All experiments were repeated three times except for high-throughput sequencing, and the results were presented as the mean \pm standard deviation. Statistical analyses were performed using GraphPad 6.0 (GraphPad 
Software, Inc.). P-values were calculated using Student's t-test. $\mathrm{P}<0.05$ was considered to indicate a statistically significant difference.

\section{Results}

Biofilm observation. Biofilm formation was observed under a phase-contrast light microscope. A large number of bacteria adhered to the coverslips and formed a community (Fig. 1). The structure of biofilms on coverslips was observed under a scanning electron microscope. The biofilms formed flake or microcolony clusters on the coverslips. Colonies were wrapped together by the mucus they secreted, forming an uneven, dense membrane structure (Fig. 2).

Comparative proteomics. A total of 1,930 protein spots were detected in all gels. The representative 2-D electrophoresis images of 20 differentially expressed protein spots (7 upregulated and 13 downregulated protein spots) between biofilms and planktonic cells are presented in Fig. 3. Most proteins were distributed in the range of isoelectric point 4-7. MALDI MS and MS/MS analysis identified 20 protein spots corresponding to 18 individual proteins, including 6 upregulated (including catalase, extracellular solute-binding protein and ubiquinol-cytochrome $\mathrm{C}$ reductase iron-sulfur subunit) and 12 downregulated ones (including elongation factor $\mathrm{Tu}$, enolase, isocitrate dehydrogenase and Chaperonin Cpn60/TCP-1; Table I).

RT-qPCR and western blot analysis. The mRNA and protein expression levels of the 18 identified proteins in 2-D electrophoresis were detected by RT-qPCR and western blot analyses, respectively. RT-qPCR analysis revealed that all of the 18 genes were downregulated in biofilms compared with planktonic cells, including elongation factor $\mathrm{Tu}$ (fold change $=-100.0$ ), enolase (fold change $=-8.6$ ), isocitrate dehydrogenase (fold change $=-9.9$ ), and Chaperonin Cpn60/TCP-1 (fold change $=-12.5$; Fig. 4A). The consistency rate with the 2-D electrophoresis results at the transcriptional level was $66.67 \%(12 / 18)$. Thus, the proteins of the 12 genes that had consistent expression trends in 2-D electrophoresis and RT-qPCR were further detected by western blot analysis. The results showed that 9 proteins were significantly downregulated and 3 were upregulated in biofilms (Fig. 5). Therefore, the 9 downregulated proteins were considered differentially expressed proteins between biofilms and planktonic cells of the A3313 strain. The fold changes of the 18 mRNAs are shown in Table II.

High-throughput sequencing and bioinformatics analyses. A total of 22,039,653 and 37,506,048 reads were generated from biofilms and planktonic cells, respectively. After pre-processing, 16,624,091 and 34,222,222 aligned reads were obtained from biofilms and planktonic cells respectively.

Based on the thresholds of q value $\leq 0.05$ and $\log 2$ (fold change) $\geq 1,157$ differentially expressed mRNAs were identified. These mRNA species were grouped in three categories defined by GO, including biological processes (including protein glycosylation, nitrogen compound metabolic process, and cell wall organization), cellular compartment (such as

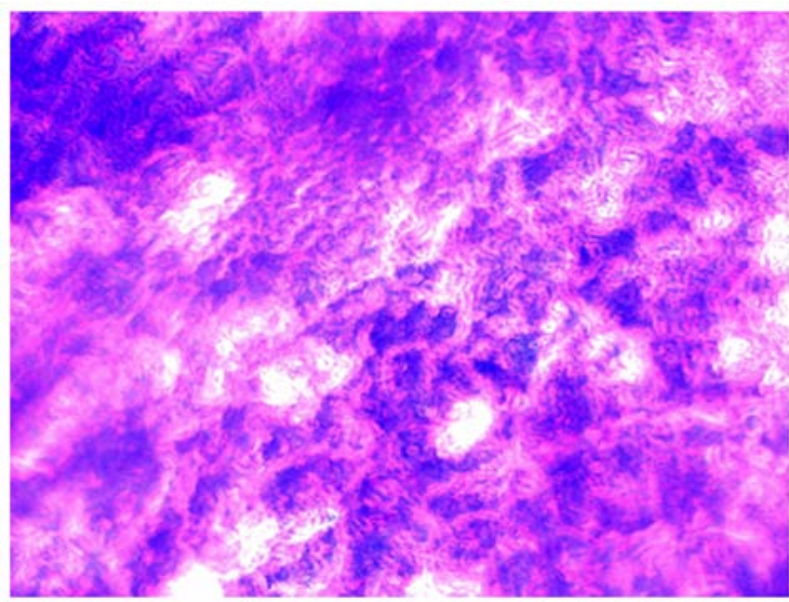

Figure 1. Observation of Brucella abortus strain isolate A3313 biofilm by crystal violet staining under a phase-contrast light microscopy. Magnification, x200.

integral component of membrane, plasma membrane, and cytoplasm), and molecular function (including DNA binding, ATP binding, and oxidoreductase activity; Fig. 6A). In addition, these differentially expressed mRNAs were significantly involved in six pathways (annotated by KEGG), including RNA degradation, sulfur metabolism, butanoate metabolism, aminoacyl-tRNA biosynthesis, aminobenzoate degradation, and selenocompound metabolism (Fig. 6B).

Confirmation of function and pathway-associated genes. RT-qPCR was performed to confirm 14 function and pathway-associated genes identified by bioinformatics analyses, including BAbS19_I10210 [ $\log 2($ fold change $)=2.67$, BAbS19_I13070 [ $\log 2$ (fold change) $=2.51]$, BAbS19_I02060 $[\log 2($ fold change $)=1.92]$, BAbS19_I03220 [ $\log 2$ (fold change) $=2.79$ ], and the results demonstrated that all of the 14 genes were upregulated in biofilms, in accordance with the sequencing results (Fig. 4B). For instance, the fold changes for the genes above (BAbS19_I10210, BAbS19_I13070, BAbS19 I02060, and BAbS19_I03220) were 13.9, 1.4, 2.3 and 9.9, respectively (Table III). These genes were considered differentially expressed genes between biofilms and planktonic cells of A3313 strain.

\section{Discussion}

Bacteria can produce an extracellular matrix that helps them adhere to inert or biological surfaces. Bacteria that colonize different surfaces and invade susceptible hosts to cause infections predominantly grow in biofilms (28). Biofilm formation is a developmental process characterized by altered expression of structural and regulatory genes (28). Most bacteria grow in biofilms, and only a small portion grow in planktonic mode (29). There have been previous studies regarding the differences between biofilms and planktonic cells for bacteria, including Lactobacillus plantarum (30), swine Brodetella bronchiseptica (31), Porphyromonas gingivalis (32) and Clostridium perfringens (33). Nevertheless, the majority of the studies focus only one aspect, either proteomic analysis or transcriptomic analysis. In the present study, the differences in both protein and gene expression levels in B.abortus cultured 

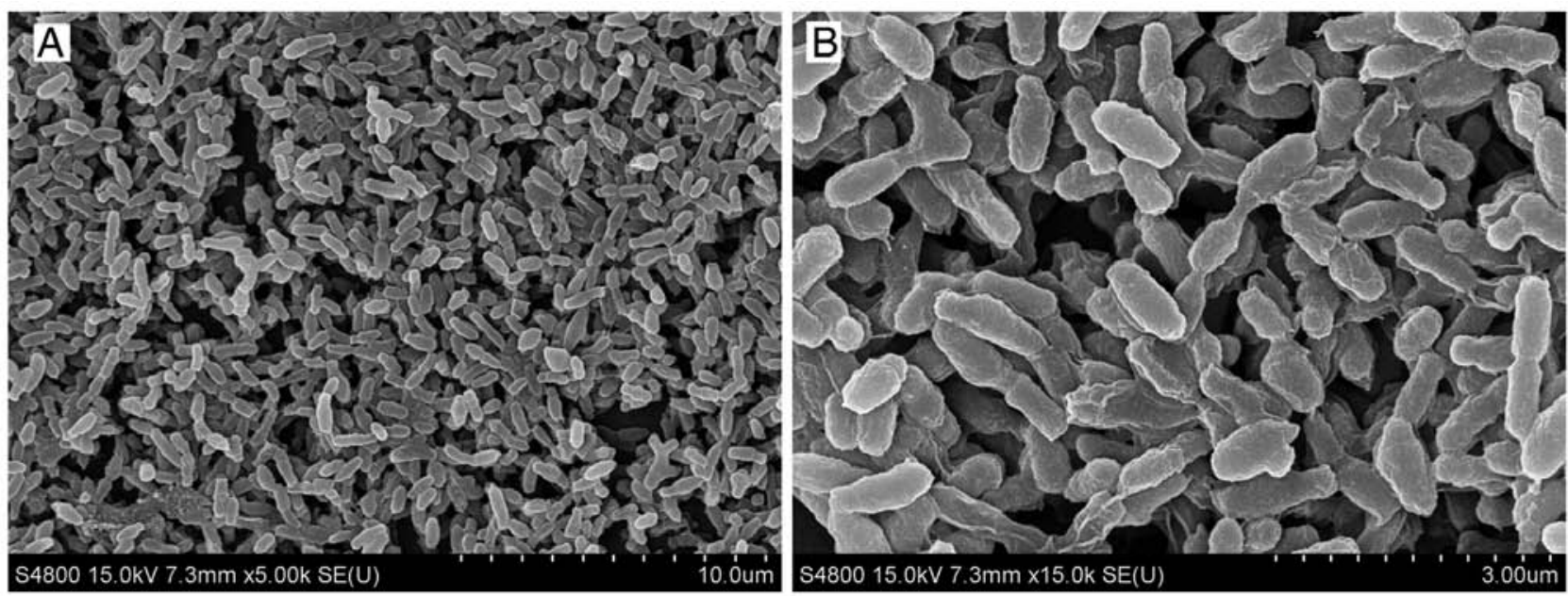

Figure 2. Scanning electron microscope images of Brucella abortus strain isolate A3313 biofilm. Magnifications, (A) x1,500 and (B) x4,000.
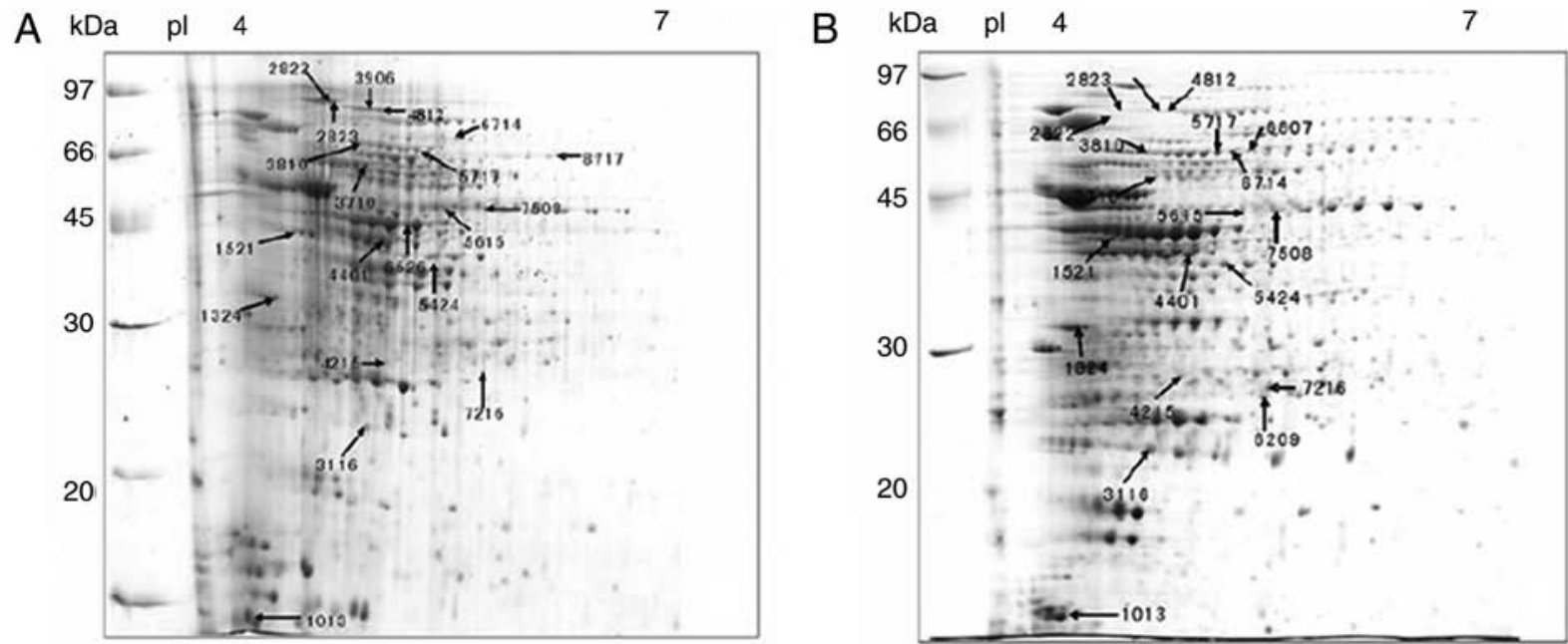

Figure 3. 2-D electrophoresis patterns of Brucella abortus A3313 from whole cell lysate proteins. B. abortus was cultured in biofilm or planktonic conditions, and the proteins were separated via 2-D electrophoresis. The proteins were separated in the first dimension by IEF and in the second dimension by SDS-PAGE. Molecular weight markers are shown in the left lane (kDa). (A) Protein pattern in the biofilm culture. (B) Protein pattern in the planktonic culture. 2-D, two-dimensional; IEF, isoelectric focusing; pI, isoelectric point.

under either biofilm or planktonic conditions were analyzed. A total of 9 downregulated proteins under conditions of biofilm growth were identified by proteomics, and 14 upregulated genes were identified in biofilm via high-throughput sequencing.

Bacteria in biofilms exhibit persistence in spite of sustained host defense (8); however, little is known regarding the host immune response to biofilm infections. The protein expression in biofilms grown in vivo is difficult to study due to the difficulty of extracting bacterial proteins from in vivo biofilms (10). The present study separated proteins via 2-D electrophoresis and analyzed with MALDI-TOF/TOF-MS to identify the differentially expressed protein spots, which included elongation factor Tu, enolase, chaperone protein DnaJ and periplasmic binding protein.

Among the differentially expressed protein spots, elongation factor Tu had a higher fold change. It was also found to have the greatest fold change in mRNA expression, which suggested the potential role of elongation factor Tu in B. abortus. Elongation factor Tu is one of the most abundant proteins in bacterial cells, involved in critical steps in protein biosynthesis and forming structural filaments in vitro (34). It has been observed on the surface of several pathogenic bacteria, including Burkholderia pseudomallei and the closely-related Pseudomonas aeruginosa $(35,36)$. It has also been demonstrated that elongation factor Tu may play a role as a bacterial virulence factor. Barel et al (37) reported that elongation factor Tu can facilitate invasion of host cells by Francisella tularensis via interaction with nucleolin. Notably, it also acts as a biofilm component in Serratia aureus (38). Thus, it was hypothesized that elongation factor Tu may be associated with virulence in B. abortus biofilm.

Enolase is an enzyme involved in the glycolytic pathway, catalyzing the reversible conversion of 2-phosphoglycerate to phosphoenolpyruvate (39). Enolase was previously regarded as a soluble glycolytic enzyme, present in cytosol exclusively (39). Enolase has been found to be a multifaceted protein with sub-cellular localizations and diverse biological functions $(40,41)$. It acts as a plasminogen receptor on the cell 


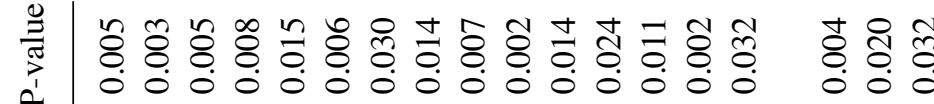

全

से

$\underset{80}{0}$

要

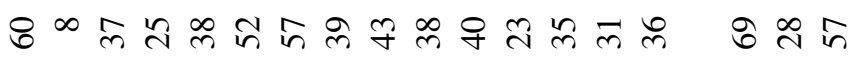

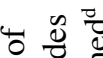

$\ln 2$

之े

(n)

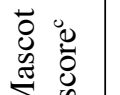

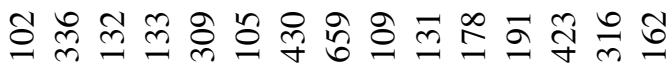

๙ ণ ले

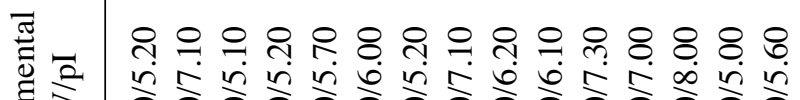

高

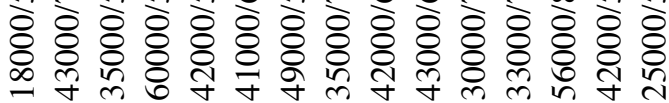

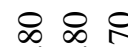

in in in

\& 8 ह

긍 त

ชี.

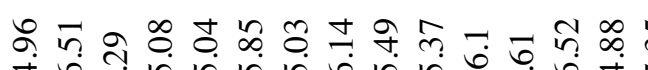

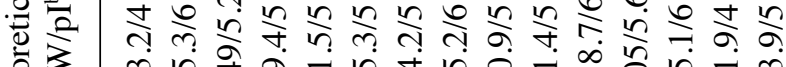

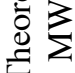

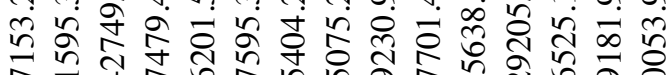

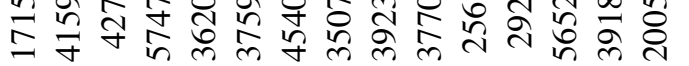

ซ. ลุ

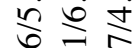

造

ชิ

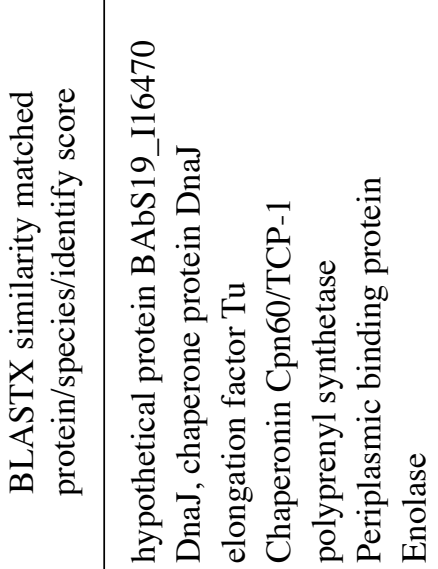

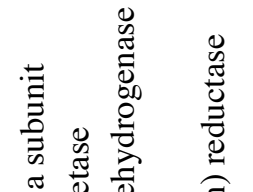

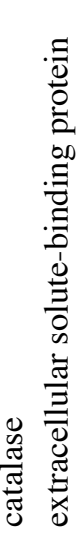

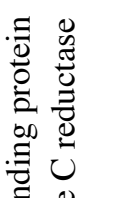

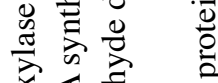

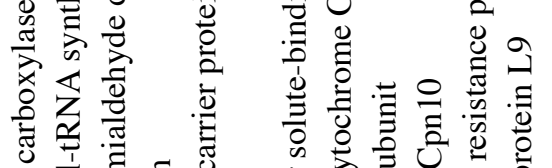

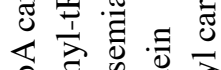

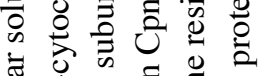

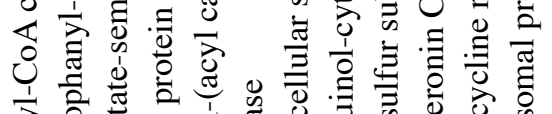

芭

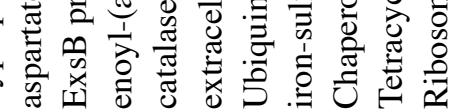

బิ

音: 总

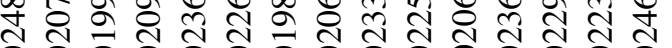

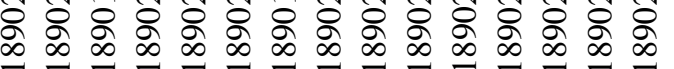

玄

के ัे ूे

के \&

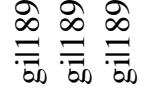

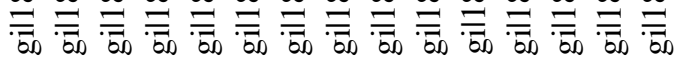

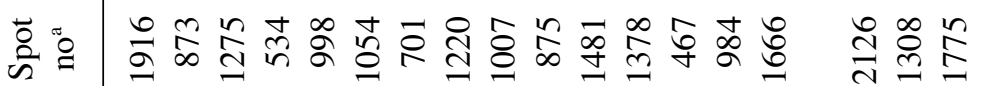

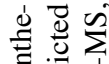

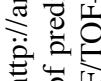

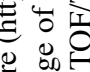

运苛

要这

突

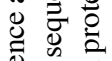

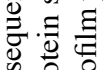

盾迸

뭉 च

氙

政 䎡

寻

品

จ

过

of

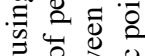

ठ্

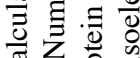

运云

웅

券部

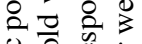

을

造 至

: $)$

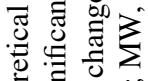

需总

.

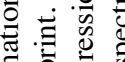

ह

总总造

$\Xi \Xi$ 击

宛啳范

青急苍

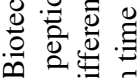

흥

过苞

ల. च

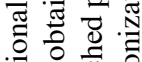

昰

$\exists$ 至

离

ह $\sum_{0}$

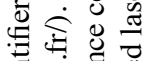

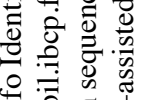

율

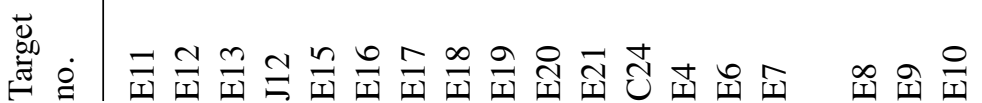



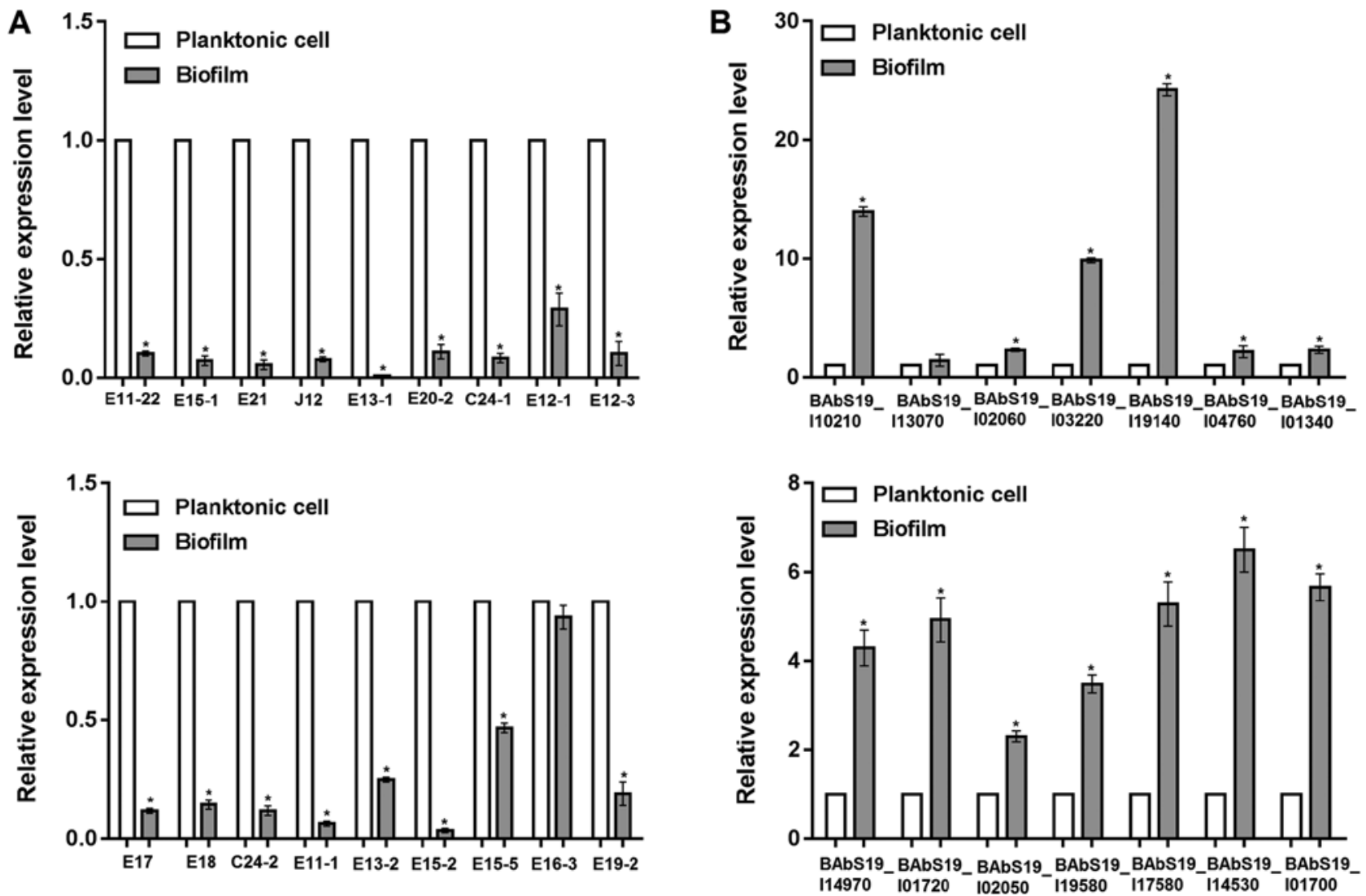

Figure 4. Differential expression of mRNAs between Brucella abortus cultured under planktonic or biofilm conditions. The relative expression levels of (A) 18 genes encoding proteins identified by 2-D electrophoresis and (B) 14 genes identified via high-throughput sequencing. 2-D, two-dimensional. "P<0.05 vs. control (planktonic cells). E11-22, hypothetical protein BAbS19_I16470; E15-1, polyprenyl synthetase; E21, ExsB protein; J12, Chaperonin Cpn60TCP-1; E13-1, elongation factor Tu; E20-2, aspartate-semialdehyde dehydrogenase; C24-1, enoyl-(acyl carrier protein) reductase; E12-1, DnaJ, chaperone protein DnaJ; E12-3, isocitrate dehydrogenase; E17, Enolase; E18, Acetyl-CoA carboxylase, alpha subunit; C24-2, putative sulfite oxidase subunit YedY; E11-1, Bacterial protein export chaperone SecB; E13-2, Antifreeze protein, type I; E15-2, Lactatemalate dehydrogenase; E15-5, Phosphoribosylformylglycinamidinecyclo-ligase; E16-3, Periplasmic binding protein; E19-2, tryptophanyl-tRNAsynthetase.
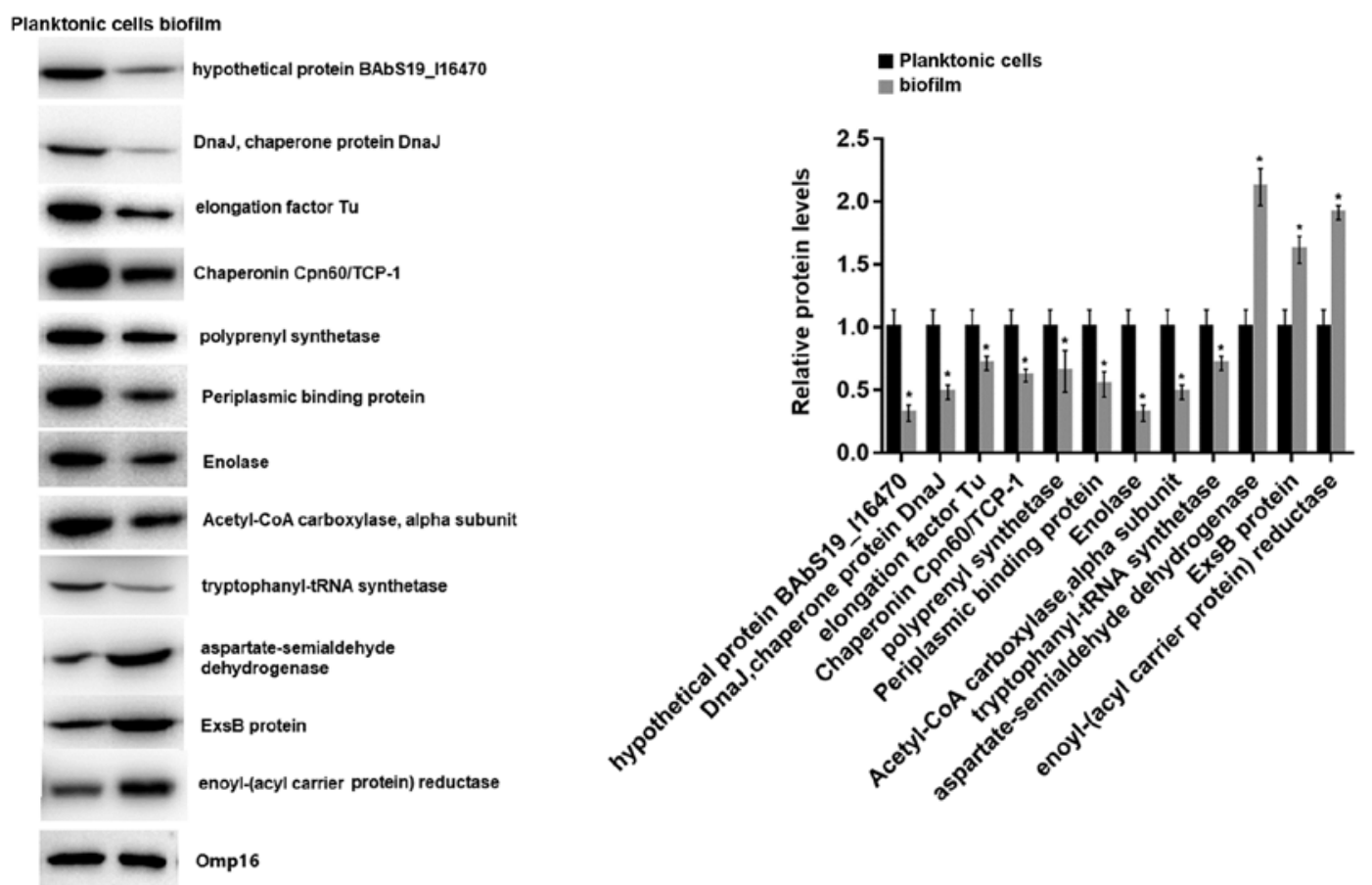

Figure 5. Analysis of differential protein expression in Brucella abortus cultured under planktonic or biofilm conditions. Western blot analysis of 12 proteins showed that 9 proteins were downregulated and 3 were upregulated between biofilms and planktonic cells. Omp16, outer membrane protein 16 . ${ }^{*} \mathrm{P}<0.05$ vs. control (planktonic cells). 
Table II. RT-qPCR identification of the mRNA expression levels of 18 proteins identified in 2-D electrophoresis.

\begin{tabular}{|c|c|c|c|}
\hline Protein spot & Protein & $\mathrm{FC}^{\mathrm{a}}$ & $\mathrm{FC}^{\mathrm{b}}$ \\
\hline E11 & hypothetical protein BAbS19_I16470 & -10.0 & -6.84 \\
\hline $\mathrm{E} 21$ & ExsB protein & -20.0 & -1.82 \\
\hline $\mathrm{C} 24$ & enoyl-(acyl carrier protein) reductase & -12.5 & -1.76 \\
\hline $\mathrm{J} 12$ & Chaperonin Cpn60TCP-1 & -12.5 & -3.16 \\
\hline E20 & aspartate-semialdehyde dehydrogenase & -9.1 & -1.88 \\
\hline E13 & elongation factor $\mathrm{Tu}$ & -100 & -4.32 \\
\hline E15 & polyprenyl synthetase & -14.3 & -2.39 \\
\hline E12 & DnaJ, chaperone protein DnaJ & -3.5 & -5.55 \\
\hline E17 & Enolase & -8.6 & -1.95 \\
\hline E18 & Acetyl-CoA carboxylase, a subunit & -7.0 & -1.95 \\
\hline E16 & Periplasmic binding protein & -1.1 & -2.19 \\
\hline E19 & tryptophanyl-tRNAsynthetase & -5.3 & -1.90 \\
\hline E4 & catalase & -33.3 & 2.41 \\
\hline E6 & extracellular solute-binding protein & -22.6 & 1.78 \\
\hline E7 & Ubiquinol-cytochrome $\mathrm{C}$ reductase iron-sulfur subunit & -25.0 & 1.70 \\
\hline E8 & Chaperonin Cpn10 & -14.3 & 1.68 \\
\hline E9 & Tetracycline resistance protein TetB & -12.5 & 1.67 \\
\hline E10 & Ribosomal protein L9 & -33.3 & 1.51 \\
\hline
\end{tabular}

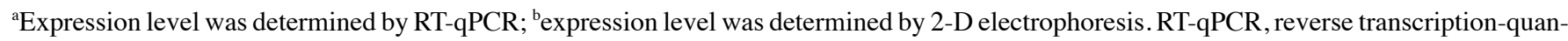
titative polymerase chain reaction; 2-D, two-dimensional; FC, fold change.

A

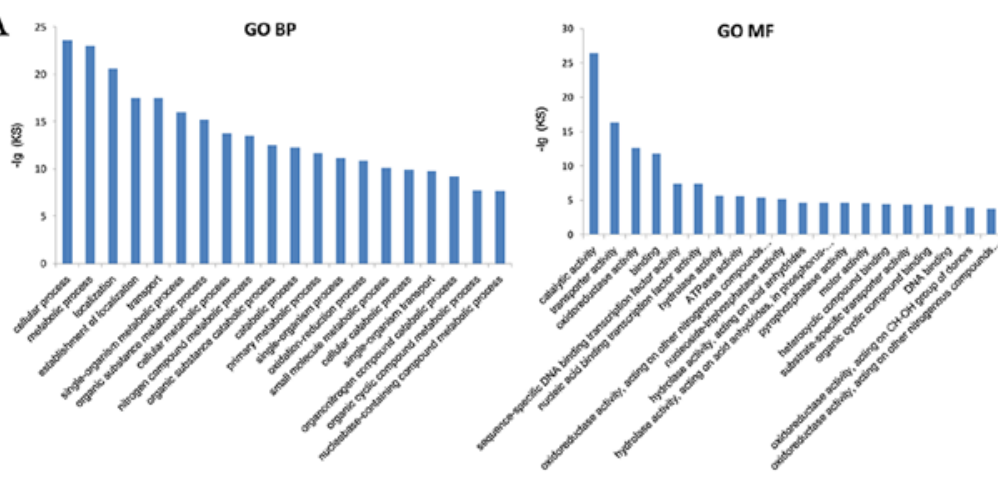

B

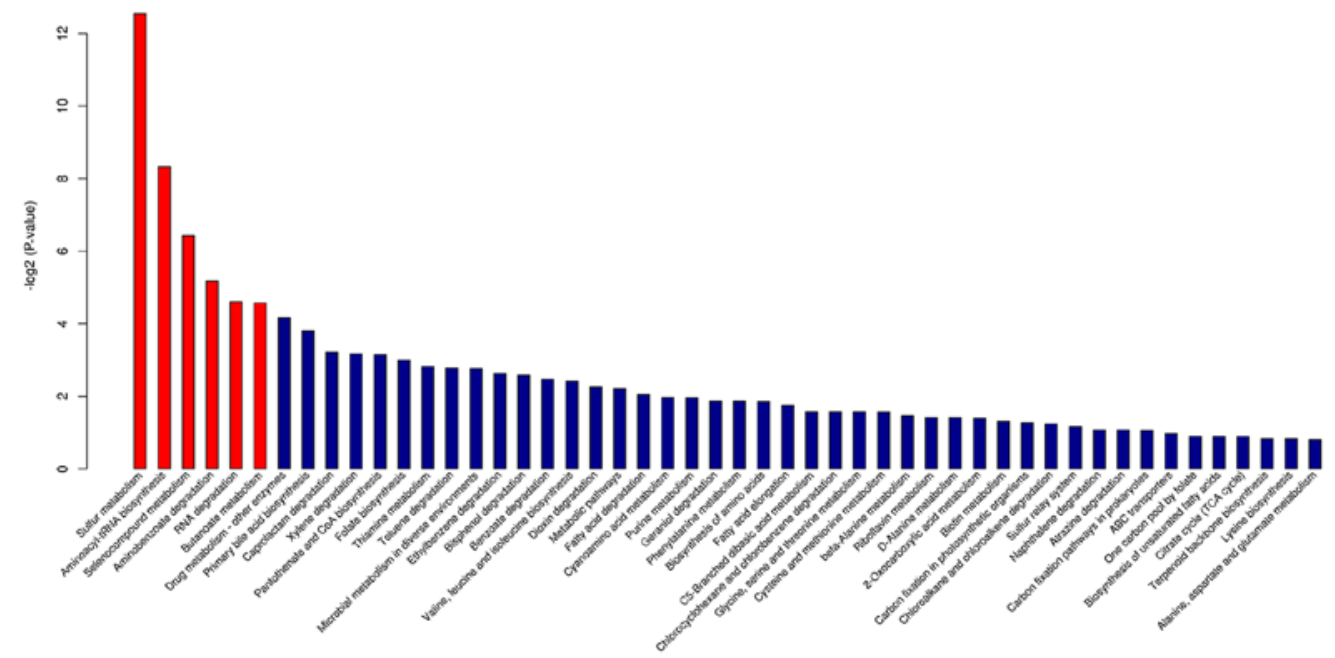

Figure 6. Functional and pathway analysis of differentially expressed genes in Brucella abortus biofilm. The significant (A) GO terms (BP, CC and MF) and (B) pathways [significant (red); not significant (blue)] enriched by differentially expressed genes. The horizontal axis represents significant GO terms and pathways, and the vertical axis represents the percentage of genes. GO, Gene Ontology; BP, biological process; MF, molecular function; CC, cellular compartment; KS, Kolmogorov-Smirnov. 


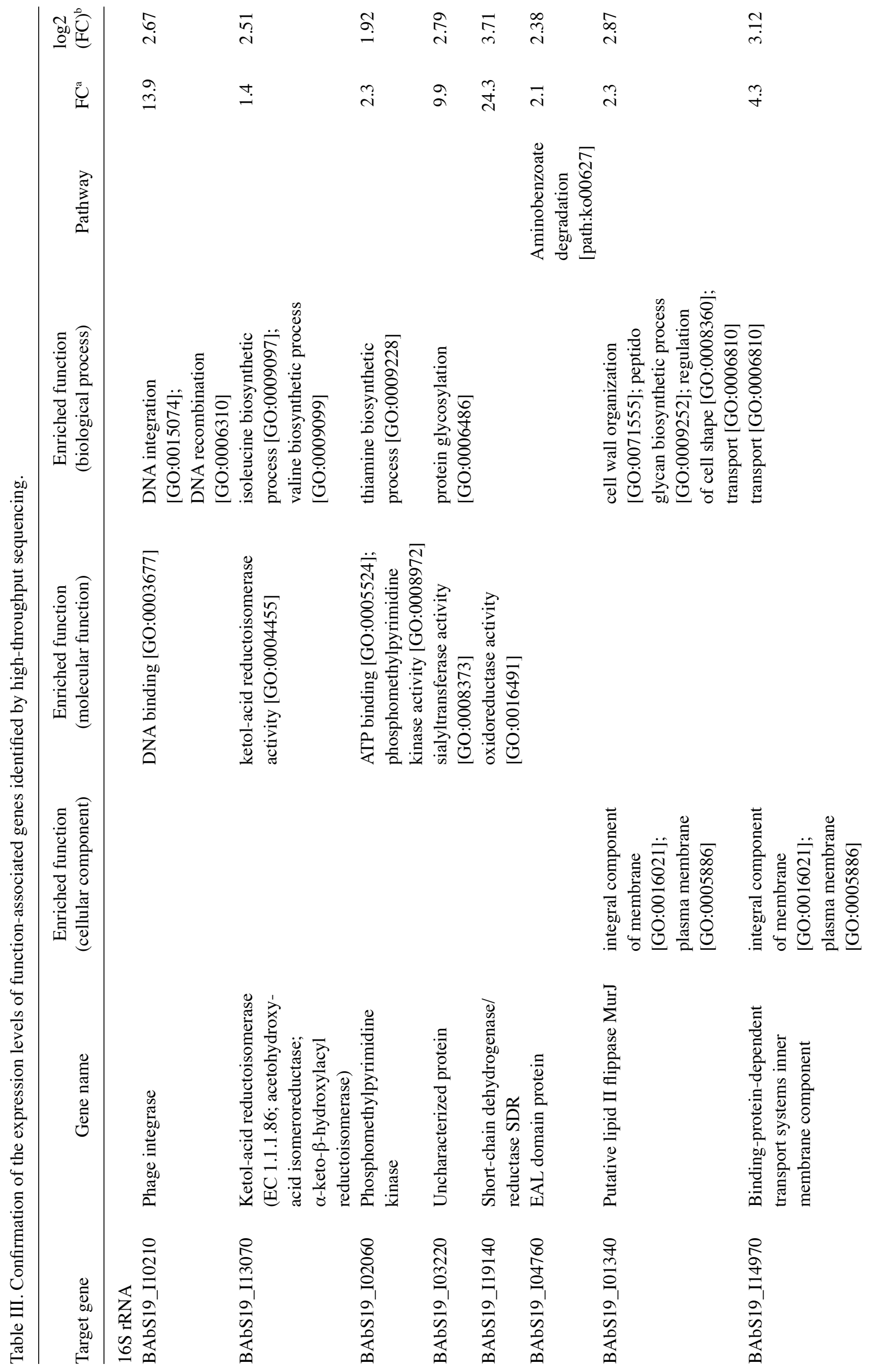




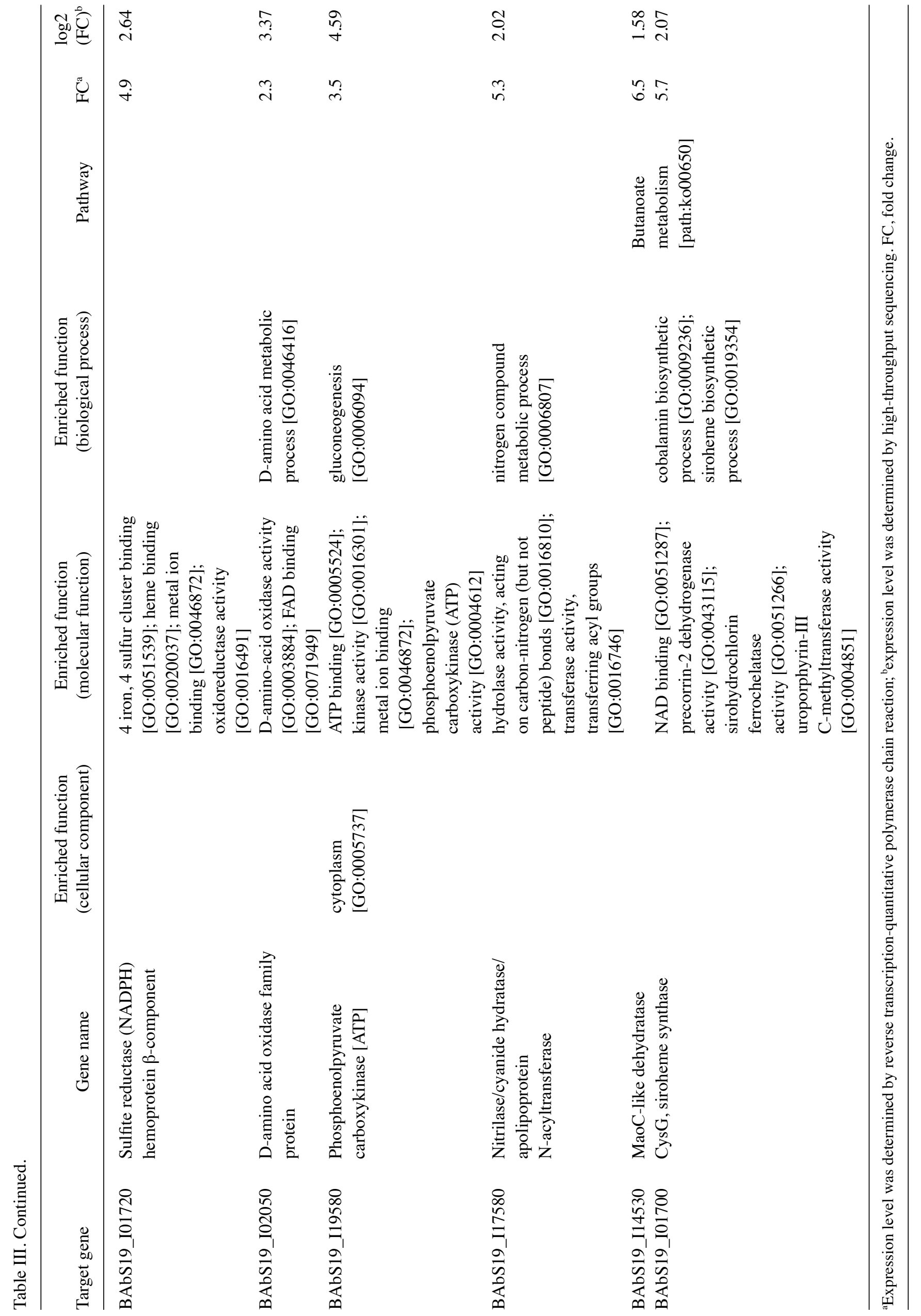


surface of various microorganisms and pathogens, and serves an important role in bacterial colonization, persistence and host tissue invasion $(42,43)$. It has been reported that in Candida albicans, enolase expresses on the surface of biofilm-forming cells and contributes to the adhesion of Candida albicans to different substrates with potential implications for biofilm adhesion and formation (44). Importantly, enolase has been cloned in B. abortus A19 and exhibits critical roles in the colonization and invasion of this pathogen (45). Specially, Han et al (45) also find that enolase protein can bind to $B$. abortus-positive sera, indicating that enolase may serve as a useful diagnostic marker for brucellosis.

DnaJ chaperone is a prototypical member of the Hsp40 family, which is important for numerous cellular functions, such as membrane lipid composition and cell division $(46,47)$. Grudniak et al (48) demonstrated that this chaperone was involved in the biofilm formation of Escherichia coli.Periplasmic binding proteins have been introduced into bacteria to function in synthetic signal transduction pathways that respond to extracellular ligands and act as biologically active enzymes (49). As for the other differentially expressed proteins, their roles in biofilm formation have not been reported to the best of the authors' knowledge. Given their differential expression between biofilm and planktonic cells, it can be hypothesized that they may be associated with the biofilm characteristics of B. abortus.

From high-throughput sequencing, 14 function- and pathway-associated genes were identified. For instance, BAbS19_I19580 was enriched in functions related to phosphoenolpyruvate carboxykinase activity [GO:0004612] and gluconeogenesis [GO:0006094]. In most organisms, phosphoenolpyruvate carboxykinase can catalyze the formation of phosphoenolpyruvate via the phosphorylation and decarboxylation of oxaloacetate, which is the first step in the gluconeogenic pathway (50). A previous study by Li et al (51) suggested that gluconeogenesis serves a key role in the development of Saccharomyces cerevisiae biofilms. It was found that during the attachment period of biofilms, the expression of gluconeogenesis pathway-associated genes was upregulated, which was consistent with the findings of the present study. Viadas et al (52) found that the expression level of phosphoenolpyruvate carboxykinase gene was increased in B. abortus with bvrR mutant compared with wild type cells. Notably, phosphoenolpyruvate carboxykinase has been reported to be an acid-induced virulence factor in Agrobacterium tumefaciens (53). Therefore, it was proposed that phosphoenolpyruvate carboxykinase serves an important role in the virulence of $B$. abortus through the functions described above.

Binding protein-dependent transport systems have been found to be closely associated with structure, organization, mechanism and evolutionary origin (54). Numerous binding protein-dependent transport systems have been identified in Gram-negative bacteria (54). The major role of the binding protein systems is to recapture substrates that leak from the cell and retain them near the cell (55). In the present study, BAbS19_I14970 (binding-protein-dependent transport systems inner membrane component) was differentially expressed between biofilm and planktonic bacteria and enriched in an integral component of membrane (GO:0016021), indicating an important role in biofilm function.
Despite the identification of differentially expressed proteins and genes between biofilm and planktonic cells, no common protein or gene was identified, which may be attributed to several reasons. First, the detectability and abundance of proteomic and genomic analyses were different. Second, only 9 differentially expressed proteins were validated in proteomics, which may affect the consistency between proteomic and genomic analyses. Third, the thresholds used in proteomic and genomic analyses were different. Of note, there were certain common genes between proteomic and genomic analyses when significant differences were disregarded. Finally, there were differences in expression between transcriptional and protein levels due to post-transcriptional and posttranslational modifications. Furthermore, there is a limitation in the present study in that only one isolate was used for the analysis. Further isolates of B. abortus will be applied in future studies to further investigate the differentially expressed proteins and genes between the two culture conditions.

In conclusion, differential expression analysis at the protein and genomic levels suggested that the proteins and genes differentially expressed in B. abortus biofilms may serve important roles in bacterial defense, colonization, invasion, and virulence.

\section{Acknowledgements}

Not applicable.

\section{Funding}

The present study was supported by the Priority Academic Program Development of Jiangsu Higher Education Institutions (grant no. PAPD), the Science Foundation of General Administration of Quality Supervision, Inspection and Quarantine of the People's Republic China (grant no. 2008IK004) and National Basic Research Program of China (973 Program; grant no. 2012CB518801).

\section{Availability of data and materials}

The datasets used and/or analyzed during the current study are available from the corresponding author on reasonable request.

\section{Authors' contributions}

TT, CL and YJ participated in the design of this study. TT, MW, LZ an AG performed the experiments. TT, GC, YX and $\mathrm{CZ}$ analyzed the data. CL, LZ and AG obtained funding. TT and YX drafted the manuscript. GC and $\mathrm{CZ}$ participated in revision of manuscript for important intellectual content. All authors read and approved the final manuscript.

\section{Ethics approval and consent to participate}

Not applicable.

\section{Patient consent for publication}

Not applicable. 


\section{Competing interests}

The authors declare that they have no competing interests.

\section{References}

1. Byndloss MX and Tsolis RM: Brucella spp. virulence factors and immunity. Annu Rev Anim Biosci 4: 111-127, 2016.

2. Hasanjani Roushan MR and Ebrahimpour S: Human brucellosis: An overview. Caspian J Intern Med 6: 46-47, 2015.

3. Atluri VL, Xavier MN, de Jong MF, den Hartigh AB and Tsolis RM: Interactions of the human pathogenic Brucella species with their hosts. Annu Rev Microbiol 65: 523-541, 2011.

4. Halling SM, Peterson-Burch BD, Bricker BJ, Zuerner RL, Qing Z, Li LL, Kapur V, Alt DP and Olsen SC: Completion of the genome sequence of Brucella abortus and comparison to the highly similar genomes of Brucella melitensis and Brucella suis. J Bacteriol 187: 2715-2726, 2005.

5. Doganay G and Doganay M: Brucella as a potential agent of bioterrorism. Recent Pat Antiinfect Drug Discov 8: 27-33, 2013.

6. Dang $\mathrm{H}$ and Lovell CR: Microbial surface colonization and biofilm development in marine environments. Microbiol Mol Biol Rev 80: 91-138, 2015.

7. Wu H, Moser C, Wang HZ, Høiby N and Song ZJ: Strategies for combating bacterial biofilm infections. Int J Oral Sci 7: 1-7, 2015.

8. Burmølle M, Thomsen TR, Fazli M, Dige I, Christensen L, Homøe P, Tvede M, Nyvad B, Tolker-Nielsen T, Givskov M, et al: Biofilms in chronic infections a matter of opportunity monospecies biofilms in multispecies infections. FEMS Immunol Med Microbiol 59: 324-336, 2010.

9. Parsek MR and Singh PK: Bacterial biofilms: An emerging link to disease pathogenesis. Annu Rev Microbiol 57: 677-701, 2003.

10. Wang Y, Yi L, Wu Z, Shao J, Liu G, Fan H, Zhang W and Lu C: Comparative proteomic analysis of streptococcus suis biofilms and planktonic cells that identified biofilm infection-related immunogenic proteins. PLoS One 7: e33371, 2012.

11. Kumon H, Ono N, Iida M and Nickel JC: Combination effect of fosfomycin and ofloxacin against Pseudomonas aeruginosa growing in a biofilm. Antimicrob Agents Chemother 39: 1038-1044, 1995.

12. Wilson M: Susceptibility of oral bacterial biofilms to antimicrobial agents. J Med Microbiol 44: 79-87, 1996.

13. Wang L, Li Y, Wang L, Zhu M, Zhu X, Qian C and Li W: Responses of biofilm microorganisms from moving bed biofilm reactor to antibiotics exposure: Protective role of extracellular polymeric substances. Bioresour Technol 254: 268-277, 2018.

14. Flury D, Behrend H, Sendi P, von Kietzell M and Strahm C: Brucella melitensis prosthetic joint infection. J Bone Jt Infect 2 : 136-142, 2017.

15. Almirón MA, Roset MS and Sanjuan N: The aggregation of Brucella abortus occurs under microaerobic conditions and promotes desiccation tolerance and biofilm formation. Open Microbiol J 7: 87-91, 2013.

16. Conde-Álvarez R, Arce-Gorvel V, Iriarte M, Manček-Keber M, Barquero-Calvo E, Palacios-Chaves L, Chacón-Díaz C, Chaves-Olarte E, Martirosyan A, von Bargen K, et al: The lipopolysaccharide core of Brucella abortus acts as a shield against innate immunity recognition. PLoS Pathog 8: e1002675, 2012.

17. Spera JM, Ugalde JE, Mucci J, Comerci DJ and Ugalde RA: A B lymphocyte mitogen is a Brucella abortus virulence factor required for persistent infection. Proc Natl Acad Sci USA 103 16514-16519, 2006.

18. Manterola L, Guzmán-Verri C, Chaves-Olarte E, Barquero-Calvo E, de Miguel MJ, Moriyón I, Grilló MJ, López-Goñi I and Moreno E: BvrR/BvrS-controlled outer membrane proteins Omp3a and Omp3b are not essential for Brucella abortus virulence. Infect Immun 75: 4867-4874, 2007.

19. Harro JM, Peters BM, O'May GA, Archer N, Kerns P, Prabhakara R and Shirtliff ME: Vaccine development in Staphylococcus aureus: Taking the biofilm phenotype into consideration. FEMS Immunol Med Microbiol 59: 306-323, 2010.

20. Yi L, Wang Y, Ma Z, Zhang H, Li Y, Zheng JX, Yang YC, Fan HJ and Lu CP: Biofilm formation of Streptococcus equi ssp. zooepidemicus and comparative proteomic analysis of biofilm and planktonic cells. Curr Microbiol 69: 227-233, 2014.

21. Wang L, Wang S and Li W: RSeQC: Quality control of RNA-seq experiments. Bioinformatics 28: 2184-2185, 2012.
22. Trapnell C, Pachter L and Salzberg SL: TopHat: Discovering splice junctions with RNA-Seq. Bioinformatics 25: 1105-1111, 2009.

23. Trapnell C, Roberts A, Goff L, Pertea G, Kim D, Kelley DR, Pimentel H, Salzberg SL, Rinn JL and Pachter L: Differential gene and transcript expression analysis of RNA-seq experiments with TopHat and Cufflinks. Nat Protoc 7: 562-578, 2012.

24. Ashburner M, Ball CA, Blake JA, Botstein D, Butler $H$, Cherry JM, Davis AP, Dolinski K, Dwight SS, Eppig JT, et al: Gene ontology: Tool for the unification of biology. The Gene Ontology Consortium. Nat Genet 25: 25-29, 2000.

25. Kanehisa M and Goto S: KEGG: Kyoto encyclopedia of genes and genomes. Nucleic acids Res 28: 27-30, 2000.

26. Wang Y, Yi L, Zhang Z, Fan H, Cheng X and Lu C: Biofilm formation, host-cell adherence, and virulence genes regulation of Streptococcus suis in response to autoinducer-2 signaling. Curr Microbiol 68: 575-580, 2014.

27. Livak KJ and Schmittgen TD: Analysis of relative gene expression data using real-time quantitative PCR and the 2(-Delta Delta C(T)) method. Methods 25: 402-408, 2001.

28. Steinberg D: Studying plaque biofilms on various dental surfaces. In: Handbook of bacterial adhesion Springer, pp.353-370, 2000.

29. Costerton JW, Stewart PS and Greenberg E: Bacterial biofilms: A common cause of persistent infections. Science 284: 1318-1322, 1999.

30. De Angelis M, Siragusa S, Campanella D, Di Cagno R and Gobbetti M: Comparative proteomic analysis of biofilm and planktonic cells of Lactobacillus plantarum DB200. Proteomics 15: 2244-2257, 2015.

31. Ning J, Gao X, Xiao M, et al: Comparative proteomic analysis between biofilm-forming cells and planktonic cells of swine Brodetella bronchiseptica. J Agric Biotechnol 26: 159-166, 2018 [In Chinese].

32. Romero-Lastra P, Sánchez MC, Ribeiro-Vidal H, LlamaPalacios A, Figuero E, Herrera D and Sanz M: Comparative gene expression analysis of Porphyromonas gingivalis ATCC 33277 in planktonic and biofilms states. PLoS One 12: e0174669, 2017.

33. Charlebois A, Jacques $M$ and Archambault M: Comparative transcriptomic analysis of Clostridium perfringens biofilms and planktonic cells. Avian Pathol 45: 593-601, 2016.

34. Furano AV: Content of elongation factor Tu in Escherichia coli. Proc Natl Acad Sci USA 72: 4780-4784, 1975.

35. Harding SV, Sarkar-Tyson M, Smither SJ, Atkins TP, Oyston PC, Brown KA, Liu Y, Wait R and Titball RW: The identification of surface proteins of Burkholderia pseudomallei. Vaccine 25: 2664-2672, 2007.

36. Kunert A, Losse J, Gruszin C, Hühn M, Kaendler K, Mikkat S, Volke D, Hoffmann R, Jokiranta TS, Seeberger H, et al: Immune evasion of the human pathogen Pseudomonas aeruginosa: Elongation factor Tuf is a factor $\mathrm{H}$ and plasminogen binding protein. J Immunol 179: 2979-2988, 2007.

37. Barel M, Hovanessian AG, Meibom K, Briand JP, Dupuis M and Charbit A: A novel receptor-ligand pathway for entry of Francisella tularensis in monocyte-like THP-1 cells: Interaction between surface nucleolin and bacterial elongation factor Tu. BMC Microbiol 8: 145, 2008.

38. Foulston L, Elsholz AK, DeFrancesco AS and Losick R: The extracellular matrix of Staphylococcus aureus biofilms comprises cytoplasmic proteins that associate with the cell surface in response to decreasing $\mathrm{pH}$. MBio 5: e01667-e01614, 2014.

39. Entelis N, Brandina I, Kamenski P, Krasheninnikov IA, Martin RP and Tarassov I: A glycolytic enzyme, enolase, is recruited as a cofactor of tRNA targeting toward mitochondria in Saccharomyces cerevisiae. Genes Dev 20: 1609-1620, 2006.

40. Pancholi V: Multifunctional a-enolase: Its role in diseases. Cell Mol Life Sci 58: 902-920, 2001.

41. Sriram G, Martinez JA, McCabe ER, Liao JC and Dipple KM: Single-gene disorders: What role could moonlighting enzymes play? Am J Hum Genet 76: 911-924, 2005.

42. Kolberg J, Aase A, Bergmann S, Herstad TK, Rødal G, Frank R, Rohde $\mathrm{M}$ and Hammerschmidt S: Streptococcus pneumoniae enolase is important for plasminogen binding despite low abundance of enolase protein on the bacterial cell surface. Microbiology 152: 1307-1317, 2006.

43. Pancholi V and Fischetti VA: alpha-enolase, a novel strong plasmin(ogen) binding protein on the surface of pathogenic streptococci. J Biol Chem 273: 14503-14515, 1998.

44. Silva RC, Padovan AC, Pimenta DC, Ferreira RC, da Silva CV and Briones MR: Extracellular enolase of Candida albicans is involved in colonization of mammalian intestinal epithelium. Front Cell Infect Microbiol 4: 66, 2014. 
45. Han X, Ding C, Chen H, Hu Q and Yu S: Enzymatic and biological characteristics of enolase in Brucella abortus A19. Mol Biol Rep 39: 2705-2711, 2012.

46. Sieńczyk J, Skłodowska A, Grudniak A and Wolska KI: Influence of DnaK and DnaJ chaperones on Escherichia coli membrane lipid composition. Pol J Microbiol 53: 121-123, 2004.

47. McCarty JS and Walker GC: DnaK mutants defective in ATPase activity are defective in negative regulation of the heat shock response: Expression of mutant DnaK proteins results in filamentation. J Bacteriol 176: 764-780, 1994.

48. Grudniak AM, Włodkowska J and Wolska KI: Chaperone DnaJ influences the formation of biofilm by Escherichia coli. Pol J Microbiol 64: 279-283, 2015.

49. Dwyer MA and Hellinga HW: Periplasmic binding proteins: A versatile superfamily for protein engineering. Curr Opin Struct Biol 14: 495-504, 2004

50. Inui M, Nakata K, Roh JH,Zahn K and Yukawa H: Molecular and functional characterization of the Rhodopseudomonas palustris no. 7 phosphoenolpyruvate carboxykinase gene. J Bacteriol 181: 2689-2696, 1999.

51. Li Z, Chen Y, Liu D, Zhao N, Cheng H, Ren H, Guo T, Niu H, Zhuang W, Wu J and Ying $\mathrm{H}$ : Involvement of glycolysis/gluconeogenesis and signaling regulatory pathways in Saccharomyces cerevisiae biofilms during fermentation. Front Microbiol 6: 139, 2015.
52. Viadas C, Rodríguez MC, Sangari FJ, Gorvel JP, García-Lobo JM and López-Goñi I: Transcriptome analysis of the Brucella abortus BvrR/BvrS two-component regulatory system. PLoS One 5: e10216, 2010.

53. Liu P, Wood D and Nester EW: Phosphoenolpyruvate carboxykinase is an acid-induced, chromosomally encoded virulence factor in Agrobacterium tumefaciens. J Bacteriol 187: 6039-6045, 2005.

54. Higgins C, Hyde S, Mimmack M, Gileadi U, Gill D and Gallagher M: Binding protein-dependent transport systems. J Bioenerg Biomembr 22: 571-592, 1990.

55. Stirling D, Hulton C, Waddell L, Park SF, Stewart GS, Booth IR and Higgins CF: Molecular characterization of the proU loci of Salmonella typhimurium and Escherichia coli encoding osmoregulated glycine betaine transport systems. Mol Microbiol 3: $1025-1038,1989$.

(i) $\Theta$ This work is licensed under a Creative Commons Attribution-NonCommercial-NoDerivatives 4.0 International (CC BY-NC-ND 4.0) License. 